\title{
Explaining adaptive shifts in body size on islands: a life history approach
}

Eric P. Palkovacs

\author{
Palkovacs, E. P. 2003. Explaining adaptive shifts in body size on islands: a life history \\ approach. - Oikos 103: 37-44.
}

\begin{abstract}
The tendency for island populations to differ in body size from their mainland relatives has been well documented, but the mechanisms for these size changes remain speculative. Explanations have typically been based on ecological interactions that directly favor either an increase or decrease in body size. While it is clear that direct ecological interactions can influence body size, life history shifts present an alternative explanation for observed insular size trends across phylogenetic groups and trophic levels. Here I describe how decreased resource availability and reduced predation pressure, the same selective forces invoked by previous hypotheses, can operate to produce body size changes via the evolution of life history traits. This mechanism is more generally applicable than previous explanations and is consistent with much of the available data.
\end{abstract}

E. P. Palkovacs, Dept of Ecology and Evolutionary Biology, Yale Univ., 165 Prospect Street, New Haven, CT 06520-8106, USA (eric.palkovacs@yale.edu).

\section{Documented body size patterns}

Insular size trends have been described in detail for terrestrial vertebrate groups including mammals and reptiles and for plants. Foster (1964) documented insular size trends in six mammal groups and concluded that insular rodents tend to increase in size and artiodactyls, carnivores, and lagomorphs tend to decrease in size, with marsupials and insectivores showing no consistent trends. Lomolino (1985) examined these same groups with increased sample sizes and confirmed Foster's observations. Insular size trends have been particularly well investigated for rodents, and a general trend towards increased body size has been confirmed (see Adler and Levins 1994 and references therein). Some particularly striking examples of size shifts in mammals include the extinct dwarf elephants of the Mediterranean, which were no bigger than ponies (Stock 1935, Hooijer 1951), and the extinct giant insectivore Deinogalerix koenigswali of Gargano, a paleoisland in southern Italy, which was larger than a fox (Freudenthal 1972).

Accepted 24 February 2003

Copyright (C) OIKOS 2003

ISSN 0030-1299

OIKOS 103:1 (2003)
In non-avian reptiles there are many striking examples of insular giants including the tortoises of the Galápagos, the unrelated giant tortoises of the Indian Ocean, and the Komodo monitor of several Indonesian islands. Iguanids and most herbivorous lizards appear to be larger on islands (Mertens 1934, Shaw 1945, Carlquist 1965, Soulé 1966, Rand et al. 1975). Caribbean Anolis, likewise, show a general increase in body size (Case 1978), although there is much variation possibly due to niche partitioning among co-occurring species (Schoener 1969). A trend towards greater size in lizards has also been shown for Scincidae, Gekkonidae, and Agamidae (Mertens 1934). Insular snakes, on the other hand, are generally smaller than their mainland relatives (Case 1978).

Plants also exhibit size changes on islands. Carlquist (1974) used the term "insular woodiness" to describe the old observation (Darwin 1859, Wallace 1878) that many plants with herbaceous mainland relatives are perennial and tree-like on islands. Detailed analyses of the flora of Hawaii (Carlquist 1980), the Canary Islands (Shmida and Werger 1992), and the Juan Fernández 
Archipelago (Bernardello et al. 2001) confirm high proportions of perennials and trends towards arborescence in many species. Molecular phylogenetic studies have revealed the repeated evolution of woodiness in groups of plants from Hawaii (Wagner et al. 1990, Givinish et al. 1995, Baldwin 1997, Sakai et al. 1997, Givinish 1998) and Macronesian islands (Böhle et al. 1996, Kim et al. 1996, Francisco-Ortega et al. 1997, Panero et al. 1999).

Several theories exist regarding the selective forces behind the evolution of insular woodiness. Some mirror theories proposed to explain body size shifts in vertebrates (described below) including ecological niche shifts, reduction in herbivory (Carlquist 1974), and intraspecific competition (Darwin 1859). However, some theories for plants, such as a release from seasonality (Carlquist 1974), a reduction in pollinator prevalence (Wallace 1878), and selection acting to counter inbreeding depression (Böhle et al. 1996) do not have analogues in the vertebrate literature. I will restrict this discussion to theories and examples that deal primarily with vertebrates, but it is important to note that a life history approach can be extended to explain observed trends for insular plants and invertebrates as well.

\section{Previous explanations}

Explanations for insular size shifts in vertebrates have focused on three primary factors that may differ between mainland and island environments: competition, predation, and resource availability. Below I describe the theories and evidence given to support these mechanisms and point out where these existing theories, which rely primarily on specific selective regimes, lack the generality to adequately explain insular body size changes across populations and taxa.

\section{Competition}

Reduced interspecific competition on islands has been suggested as a cause for increased body size (Sondaar 1977, Lomolino 1985). Since species richness declines with decreasing island size (MacArthur and Wilson 1967), small islands should have fewer competitors vying for limited niche space compared with the mainland, which could potentially result in empty niches. If larger individuals have greater niche breadths and can, for instance, eat large as well as small food items (Brooks and Dodson 1965), selection would favor an overall increase in size (Van Valen 1965, Roughgarden 1972, Brown 1975, Lister 1976). Supporting this view, Heaney (1978) suggests that Southeast Asian tri-colored squirrels may have increased body sizes on medium sized islands relative to large islands because of the greater diversity and abundance of interspecific competitors on the larger islands.
This niche expansion hypothesis involves selection operating directly on body size and, although plausible, its generality is questionable. For instance, this scenario rests on the assumption that increasing body size expands niche breadth and that this advantage outweighs any cost associated with growing to a larger size. Increased body size might indeed increase niche breadth for organisms feeding on particulate food items such as seeds. However, for organisms that do not handle food resources in a size specific way, it is difficult to envision how size changes would affect feeding niche (Maiorana 1990). In addition, size might not be the most sensitive or malleable character associated with niche breadth. Feeding behavior or the morphology of feeding structures may be more sensitive to selection favoring the use of an expanded resource base. Van Damme (1999), in examining correlations between body size, dietary shifts, and insularity in Lacertid lizards within a phylogenetic framework, found a significant association between transitions to insularity and extensions of the diet to include plant material. However, this study uncovered no consistent trends in body size changes.

The niche expansion hypothesis also assumes that increased niche breadth will be favored over specialization on particular food resources. A well-known example of specialization followed by speciation would include the resource partitioning based on seed size and complementary morphological changes seen in Darwin's finches of the Galápagos (Grant 1986, Petren et al. 1999). The relative advantages of increasing niche breadth versus resource partitioning are not well known.

\section{Predation}

It has often been suggested that the force of predation on islands will be less than on the mainland (Foster 1964, Sondaar 1977, Heaney 1978, Lawlor 1982, Crowell 1986, Adler and Levins 1994). The explanation usually given for such a claim is that islands support fewer predators than the mainland because both prey abundance and space are more limited. In many cases, island size does show the predicted positive correlation with predator abundance (Tamarin 1978, Crowell 1983, 1986); however, this is not always so. In Hasegawa's (1994) study of the lizard Eumeces okadae on Japanese islands, predator assemblages and hence predation pressure appears to be more closely associated with an island's distance from Japan than with island size. Therefore, island size may not always be the best predictor of relative predation pressure. Nonetheless, it remains plausible that predation pressure on islands will generally be lower than on the mainland due to limited space, prey abundance, or colonizing ability.

Most of the theories built around predation as a causal factor contributing to changes in insular body 
size have focused on the direct effects of predation as it relates to predator choice and prey evasion (Sondaar 1977, Heaney 1978, Lawlor 1982). If, for instance, predators actively choose smaller prey items on the mainland, then the colonization of a predator-free island will release the population from this selection pressure, and body size will attain its optimum point minus predation. This idea has been extended to explain the observed pattern of small insular mammals becoming large and large mammals becoming small (Sondaar 1977, Heaney 1978, Lawlor 1982, Maiorana 1990). If small mammals escape predation by hiding, favoring small body size, and large mammals escape predation by running or fighting, favoring large body size, then release from predation will result in a general increase in size for small mammals and a general decrease for large mammals. There is empirical evidence for size-specific predation and prey size refugia, particularly in fish, amphibians, and invertebrates (Werner and Gilliam 1984, Chase 1999), although such phenomena may be less important for populations of mammals and birds, which tend to show less intraspecific size variation (Werner and Gilliam 1984).

An idea central to life history theory - and touched upon by Adler and Levins (1994) in their review of insular size trends in rodents - is that predation may alter size indirectly simply by increasing mortality rates. Release from predation will reduce overall mortality, resulting in shifts in age and size at maturity (Stearns and Crandall 1981, 1984, Stearns and Koella 1986, Kozlowski and Wiegert 1987, Berrigan and Koella 1994, Abrams et al. 1996, Abrams and Rowe 1996, Day and Rowe 2002). Unlike the direct effects of predation on body size, this life history mechanism does not depend on a particular selective regime and will operate under any island conditions that produce a change in extrinsic mortality rates relative to those on the mainland. Therefore, its explanatory scope extends beyond predation. Such a general causal mechanism will be more likely to account for general trends in insular body size than will more specific mechanisms, as described below.

\section{Resource availability}

Finally, the importance of resource availability on islands has been widely suggested as a force driving shifts in body size (Foster 1964, Case 1978, Heaney 1978, Lawlor 1982, Melton 1982, Lomolino 1985). In some sense, explanations based on resource limitation are intimately related to those based on competition, but here the emphasis has been on altering size to cope with lower resource levels rather than on increasing niche breadth to exploit additional resources. The idea that resources limit body size has been employed to explain why large bodied mammals show dwarfism on islands, the concept being that larger animals require more energy intake than small animals and therefore should be more resource limited (Foster 1964, Heaney 1978, Melton 1982). The relative degree of resource limitation experienced by mammals of different sizes in the same environment has not been examined in detail. It seems likely, however, that characteristics of an organism other than body size, such as constraints on diet or feeding behavior, will have an equal or even greater impact on an organism's susceptibility to resource limitation than will body size. Lawlor (1982), in examining lagomorphs and rodents occupying 30 islands off the coast of Baja California, concluded that species with specialized diets are more susceptible to resource limitation and, therefore, have a greater tendency towards dwarfism on islands than more generalist feeders. Although resource availability is commonly thought to be lower on islands than on the mainland, the difference is hard to quantify. This problem has made testing predictions of insular body size based on resource availability difficult (Case 1978).

\section{A life history approach}

The explanations described above rely primarily upon selection acting directly on body size through the processes traditionally focused on by community ecologists - competition, predation, and resource limitation. Such direct selective pressures may, in certain cases, operate to change body size after an island has been colonized. However, a more general explanation may be better at accounting for the widely observed trends. Life history theory provides a framework for such an explanation. Many elements in any organism's life history (e.g. size at birth, age and size at maturity, age specific birth and death rates, etc.) are coupled and are involved in intrinsic trade-offs (for instance if an organism reproduces earlier it has less time to grow). Therefore, changes in one life history trait are likely to affect the values of other traits as selection acts to maximize lifetime reproduction (Gadgil and Bossert 1970). In particular, decreased extrinsic mortality due to lowered predation pressure and decreased resource availability are selective pressures that may alter the elements of an organism's life history to which adult body size is sensitive. They are also changes likely to be encountered by organisms on islands.

Upon colonizing an island, organisms' reactions to decreased extrinsic mortality rate and reduced resource levels will consist of an evolutionary (genetic) response and a phenotypically plastic response. The evolutionary response represents a shift in the position of the agesize reaction norm (the set of phenotypes expressed by a single genotype over a range of environmental conditions). The plastic response results from a slide along 
this reaction norm. Age and size at maturity are determined by the point of intersection of the reaction norm with the organism's individual growth curve (Fig. 1). Decreased individual growth rate associated with resource limitation is expected to shift the individual growth curve down, while decreased mortality associated with reduced predation should shift the reaction norm up and to the right (Stearns 1992). The relative significance of the shifts in these curves will determine
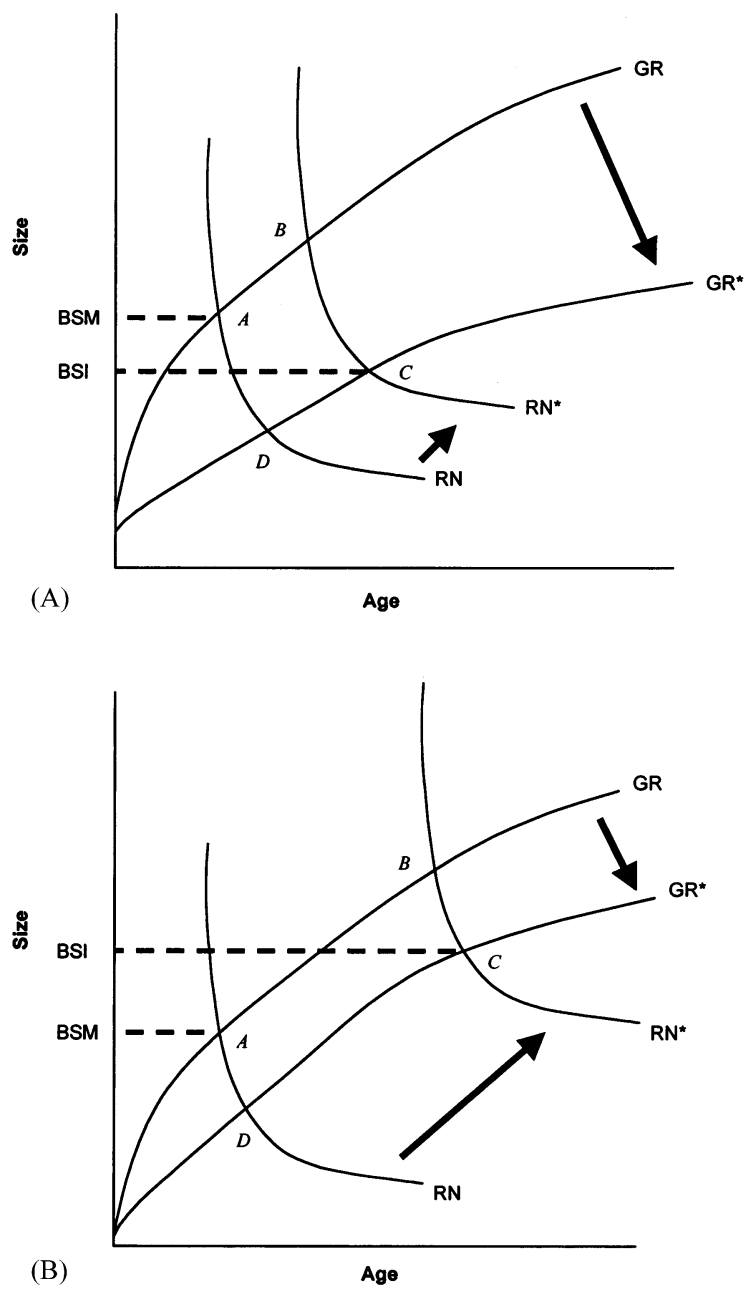

Fig. 1. The change in adult body size on an island (BSI) relative to that on the mainland (BSM) will be determined by the relative magnitude of shifts in the individual growth rate curve (mainland - GR, island - GR*) and the reaction norm determining age and size at maturity (mainland $-\mathrm{RN}$, island - $\mathrm{RN}^{*}$ ). (A) When reduced resource availability predominates, the effect of reduced individual growth rate (shift from GR to $\mathrm{GR}^{*}$ ) is of greater magnitude than the effect of reduced extrinsic mortality (shift from $\mathrm{RN}$ to $\mathrm{RN}^{*}$ ), and the resulting island body size evolves to be smaller than the ancestral mainland body size. (B) When decreased predation rate predominates, the effect of reduced extrinsic mortality rate (shift from $\mathrm{RN}$ to $\mathrm{RN}^{*}$ ) is greater than the effect of reduced growth (shift from GR to GR*), and body size evolves to be larger on the island. whether resource limitation predominates and adult body size decreases (Fig. 1A) or whether reduced mortality predominates and body size increases (Fig. 1B).

It is important to point out that life history models that describe growth as an individual growth curve (Stearns and Crandall 1981, 1984, Stearns and Koella 1986, Kozlowski and Wiegert 1987, Berrigan and Koella 1994, Day and Rowe 2002), as depicted in Fig. 1 , assume that growth rate is fixed by environmental conditions. While this assumption makes for more tractable models, it does not hold if organisms can adaptively alter their growth rates (Gotthard et al. 1994). In particular, plasticity in growth has been shown for organisms that must balance the benefits of growth against the increased risk of predation incurred when actively foraging (Lima and Dill 1990, Lima 1998). Therefore, models incorporating flexible growth rates have been devised for predicting optimal age and size at maturity (Abrams et al. 1996, Abrams and Rowe 1996). In general, the predictions of flexible-growth models are consistent with those of fixed-growth models for body size but may differ for age at maturity. Since size is the trait of primary interest, and because fixed-growth models can be analyzed graphically, I use a fixed-growth approach for describing the applicability of life history theory to the problem of insular body size. However, this is not an endorsement of the fixedgrowth approach but, rather, represents the choice of graphical tractability over biological accuracy for the purpose of this discussion.

\section{Effects of reduced resource availability}

Resource availability is able to influence adult body size through its effect on individual growth rate. Lowered resource availability will reduce growth rate if individuals must expend more time or energy to acquire food resources, such as greater travel distance between patches or increased interference competition for access to patches. The assumption of no relationship between mortality rate and growth rate produces an L-shaped reaction norm as shown in Fig. 1, but other assumed relationships between mortality and growth produce reaction norms with a variety of other shapes (Stearns and Koella 1986, Berrigan and Koella 1994).

Diagrammatically, if there is a decrease in extrinsic mortality associated with island colonization, the reaction norm is expected to shift up and to the right, resulting in an increased body size (Fig. 1A, point B). However, if resource limitation is of greater importance than reduced extrinsic mortality, the drop in individual growth rate as population density nears carrying capacity and the subsequent slide along the new reaction norm will result in a net decrease in body size (Fig. 1A, point C). Additionally, a severely limited resource supply compared to the mainland will result in a lower 


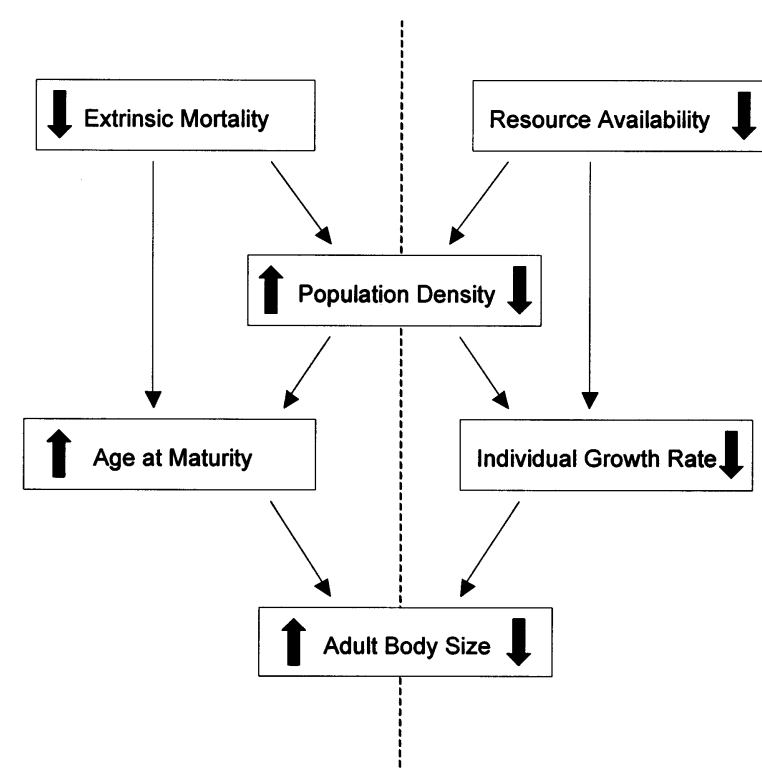

Fig. 2. The proposed network of associations leading to shifts in adult body size on islands. Upon colonization of an island, organisms may face two common environmental differences relative to the mainland, decreased extrinsic mortality and decreased resource availability. These factors will either increase or decrease (black arrows) population densities and life history traits relative to the mainland population and result in either an increased or decreased body size depending on whether the effects of decreased extrinsic mortality or decreased resource availability predominate.

carrying capacity for some island populations. This generates the following predictions for islands where reduced resource availability predominates (right side of Fig. 2): (1) decreased individual growth rate, (2) increased age at maturity, (3) decreased adult body size, and (4) decreased population density.

\section{Effects of decreased extrinsic mortality}

Kozlowski (1991) has pointed out that small organisms are usually small not because being small has direct advantages in terms of survival or fecundity, but because growing large incurs a heavy cost in terms of time and energy. If mortality risk is high, then investment in growth will not pay-off in terms of fecundity, for the risk of dying before reproducing outweighs the potential gains in reproduction associated with reproducing at a larger size. Therefore, optimal size is strongly dependent on extrinsic mortality rate. This trend is evident across mammals. In a comparative study, Promislow and Harvey (1990) found mortality rates in general, and juvenile mortality rates in particular, to be highly correlated with other life history traits.

Models focused on predicting optimal age and size at maturity have shown that decreasing mortality rate has the effect of increasing age and size at maturity, and empirical studies confirm this relationship. This is because there is generally a positive relationship between body size and fecundity, so if there is a good likelihood of surviving long enough to grow large, there will be a pay-off in terms of offspring. Stearns et al. (2000) allowed populations of Drosophila to evolve in response to experimentally manipulated conditions of high and low mortality. Consistent with predictions, they found faster development, smaller body size, and earlier peak fecundity in populations kept at conditions of high mortality and slower development, larger body size, and later peak fecundity in populations kept at conditions of low mortality. Reznick et al. (1996) examined mortality rates and life history traits in Trinidadian guppies and found that guppy populations that suffered from uniformly high predation rates across all size classes matured earlier, grew faster, and were smaller at birth and at maturity than guppies from low predation populations. In addition, they found that moving populations from high to low predation localities resulted in the evolution of life history traits typical of low predation populations.

On islands with few predators, this means that individuals that delay maturity and reproduce at a larger size will have higher fitness than those that follow the high predation risk mainland strategy and mature early and reproduce small. But what are the consequences of this life history shift in terms of population density? Since extrinsic mortality rate is lower and fecundity increases as individuals reproduce at a larger size, the population will increase in density relative to that of the mainland. This may lead to a shift that further favors increases in body size. For many organisms, a trade-off has been shown to exist between number and size of offspring. At higher population densities, with the instantaneous rate of population growth (r) near zero and the net reproductive rate $\left(\mathrm{R}_{\mathrm{o}}\right)$ near one, life histories become increasingly sensitive to changes in juvenile mortality rate. Therefore, the shift to larger offspring with improved survival may be increasingly favored over other possible alternatives to increase fitness as the population nears carrying capacity (Stearns 1992).

A decrease in extrinsic mortality will shift the age-size reaction norm up and to the right as a population with greater expected future survival increases fitness by maturing later and at a larger size than its mainland ancestor (Fig. 1B, point B). A subsequent increase in population density may result in intraspecific competition for food resources. Assuming that this competition makes resources limiting, the individual growth curve will shift down and the optimal age and size at maturity will slide along the new reaction norm. If this shift in individual growth rate is small compared to the shift in the reaction norm associated with decreased predation, the organism will mature later and at a larger size (Fig. $1 \mathrm{~B}$, point $\mathrm{C}$ ). This generates the following predictions on islands where decreased extrinsic mortality predomi- 
nates (summarized on the left side of Fig. 2): (1) increased age at maturity, (2) increased adult body size, (3) increased fecundity reflected either in the number or, more likely, in the size of offspring, and (4) increased population density.

Therefore, based on a life history framework, body size differences in island populations compared with their mainland progenitors are the results of adaptive changes in age and size at maturity and depend primarily on the relative importance of two factors, extrinsic mortality rate and resource availability. This approach is applicable under all island situations where either mortality rate or resource availability differs from the mainland and provides testable predictions about how body size, life history traits, and population density adjust to insularity.

\section{Empirical evidence}

Although no single study has measured all of the parameters required to either confirm or refute this conceptual model, there is empirical evidence of its utility. Some widely observed patterns conform to predictions. For instance, resource limitation is tightly linked with trophic position. Organisms high in the food web, such as top predators, are likely to be limited by food supply, whereas organisms in lower trophic levels, such as herbivores or granivores, are more likely to be predator limited (Wilbur et al. 1974). As expected, snakes and mammalian carnivores generally show decreased insular body size, and herbivorous lizards, artiodactyls, and rodents generally show increased insular body size, signs that resource limitation on islands is important for predators and that decreased mortality rate due to release from predation is important for herbivores.

Many studies have documented higher population densities, lower fecundities, and larger egg or offspring sizes on island compared to the mainland (Stamps and Buechner 1985). One example is in the shrew Crocidura suaveolens. Fons et al. (1997) showed that adult body size is larger and the number of pups per litter is smaller on Corsica than on the mainland. In addition, birth weight of Corsican pups is nearly twice that of mainland pups. These differences were persistent over three laboratory generations, suggesting that they are due to genetic difference rather than plasticity alone and are consistent with predictions based on reduced extrinsic mortality as the key factor in determining insular body size.

Larger body size has been attributed to better survival in rodents, including deermice on islands in British Columbia (Melton 1982), bank voles living in subalpine habitats in the French Alps (Yoccoz and Mesnager 1998), and woodrats on islands off Baja
California (Smith 1992). Subalpine bank voles have larger sizes, lower mortality rates, and higher population densities than populations of bank voles elsewhere in Europe. Although Yoccoz and Mesnager (1998) could not directly attribute the differences in mortality rates to predation, they speculate that the absence of the weasel Mustela nivalis from most subalpine habitats plays a key role. Perhaps more convincingly, Smith (1992) examined body size in insular woodrat populations on thirteen islands off the coast of Baja California and found a significant relationship between increased body size relative to the most probable mainland progenitor and the absence of mammalian predators.

Adler and Levins (1994) reviewed a detailed list of studies showing that larger body size in island rodents is generally accompanied by delayed age at maturity and higher population density. In reviewing the literature, I could find no reports of cases in which island populations with increased population density showed earlier age at maturity than their mainland relatives, although delayed maturity is a common trend. These patterns are consistent with the predictions made from decreased extrinsic mortality as the primary driver in the evolution of insular body size in these populations.

There is also empirical support for reduced resource availability acting to change life history traits and adult body size. Slower growth caused by resource limitation has been found in insular Anolis species compared to their mainland relatives (Andrews 1976). As described above, reduced growth rate is expected to be associated with a decrease in body size. Case (1978), however, suggests that average Anolis body sizes are larger on islands than on the mainland. This finding could indicate that, along with reduced individual growth rate, insular Anolis species have experienced sufficiently reduced predation rates to produce a large shift in the reaction norm up and to the right. A large enough shift in the reaction norm relative to the reduction in growth rate would result in island Anolis species growing more slowly and maturing larger than their mainland ancestors.

One detailed study of island lizard populations has measured many of the parameters necessary for evaluating this model and provides support for the accuracy of its predictions. Hasegawa (1994) conducted a study that directly examined mortality rates, resource abundance, and life history traits for populations of the lizard Eumeces okadae on a host of Japanese islands. These islands were classified into one of three groups based on the lizard's life history characteristics. The closest islands to the mainland generally have the full assemblage of mainland predators, including carnivorous mammals, snakes, and predatory birds; on these islands predation pressure was the most intense. On islands of intermediate distance from the mainland, snake and avian predators produced an intermediate level of predation pressure, and on distant islands with 
only avian predators, predation was severe on hatchlings but considerably lower on adults. Resource availability was highest on far islands and lowest on near islands. The data show that lizards on near islands exist at low population densities and have the suite of traits predicted when resource availability is the controlling variable (small adult body size, large clutch size, and small egg size), and lizards on far islands live at much higher densities and appear to have the traits predicted when decreased extrinsic mortality dominates (large adult body size, small clutch size, and large egg size). However, a true empirical test of this life history approach requires the mainland progenitor be identified by rigorous phylogenetic analysis and the correct partitioning of the genetic and plastic responses be achieved by common environment or reciprocal transplant experiments.

\section{Conclusions}

A life history approach provides a possible evolutionary mechanism for explaining size shifts commonly seen in insular populations. This approach does not rely on particular selective pressures but on general life history responses to environmental changes commonly encountered on islands. Therefore, it has a broader range of explanatory value than previous hypotheses based on selection acting directly on body size. As suggested by previous island studies, reduced extrinsic mortality rate and decreased resource levels are changes likely faced by island-colonizing populations. In a life history context, these factors may be expected to result in genetic and phenotypically plastic responses in age and size at maturity, and the relative significance of these responses will determine the direction and degree of body size change relative to the mainland ancestor. In general, reduced extrinsic mortality rate is expected to result in a body size increase and reduced resource availability is expected to result in a body size decrease. Observed patterns appear to conform to the predictions generated by this approach, but more studies of the ecological conditions and life history traits of insular populations and their mainland progenitors would be informative.

Acknowledgements - I would like to thank Stephen Stearns for providing many insights that helped to shape this discussion, and Catherine Burns and Mark Urban for offering useful comments on a draft of the manuscript.

\section{References}

Abrams, P. A., Leimar, O., Nylin, S. and Wiklund, C. 1996 The effect of flexible growth rates on optimal sizes and development times in a seasonal environment. - Am. Nat. 147: $381-395$.

Abrams, P. A. and Rowe, L. 1996. The effects of predation on the age and size of maturity of prey. - Evolution 50: $1052-1061$.
Adler, G. H. and Levins, R. 1994. The island syndrome in rodent populations. - Q. Rev. Biol. 69: 473-490.

Andrews, R. M. 1976. Growth rate in island and mainland anoline lizards. - Copeia 1976: 447-482.

Baldwin, B. G. 1997. Adaptive radiation of the Hawaiian silversword alliance: congruence and conflict of phylogenetic evidence from molecular and non-molecular investigations. - In: Givinish, T. J. and Systma, K. J. (eds), Molecular evolution and adaptive radiation. Cambridge Univ. Press, pp. 103-128.

Bernardello, G., Anderson, G. J., Stuessy, T. F. and Crawford, D. J. 2001. A survey of floral traits, breeding systems, floral visitors, and pollinator systems of the angiosperms of the Juan Fernández Islands (Chile). - Bot. Rev. 67: 255308 .

Berrigan, D. and Koella, J. C. 1994. The evolution of reaction norms: simple models for age and size at maturity. - J. Evol. Biol. 7: 549-566.

Böhle, U. R., Hilger, H. H. and Martin, W. F. 1996. Island colonization evolution of the insular woody habit in Echium L. (Boraginaceae). - Proc. Natl Acad. Sci. USA 93: $11740-11745$

Brooks, J. L. and Dodson, S. I. 1965. Predation, body size, and composition of plankton. - Science 150: 28-35.

Brown, J. H. 1975. Geographical ecology of desert rodents. In: Cody, M. L. and Diamond, J. L. (eds), Ecology and evolution of communities. Harvard Univ. Press, pp. 315 341.

Carlquist, S. 1965. Island life. - Natural History Press.

Carlquist, S. 1974. Island biology. - Columbia Univ. Press.

Carlquist, S. 1980. Hawaii a natural history, 2nd ed. - SB Printers, Inc.

Case, T. J. 1978. A general explanation for insular body size trends in terrestrial vertebrates. - Ecology 59: 1-18.

Chase, J. M. 1999. Food web effects of prey size refugia: variable interactions and alternative stable equilibria. Am. Nat. 154: 559-570.

Crowell, K. L. 1983. Experimental zoogeography: introductions of mice to small islands. - Am. Nat. 107: 535-558.

Crowell, K. L. 1986. A comparison of relict versus equilibrium models for insular mammals of the Gulf of Maine. - Biol. J. Linn. Soc. 28: 37-64.

Darwin, C. 1859 . The origin of species by means of natural selection. - John Murray.

Day, T. and Rowe, L. 2002. Developmental thresholds and the evolution of reaction norms for age and size at life-history transitions. - Am. Nat. 159: 338-350.

Fons, R., Poitevin, F., Catalan, J. and Croset, H. 1997. Decrease in litter size in the shrew Crocidura suaveolens (Mammalia, Insectivora) from Corsica (France): evolutionary response to insularity? - Can. J. Zool. 75: 954-958.

Foster, J. B. 1964. Evolution of mammals on islands. Nature 202: 234-235.

Francisco-Ortega, J., Crawford, D. J., Santos-Guerra, A. and Jansen, R. K. 1997. Origin and evolution of Argyranthemum (Asteraceae: Anthemideae) in Macronesia. - In: Givinish, T. J. and Systma, K. J. (eds), Molecular evolution and adaptive radiation. Cambridge Univ. Press, pp. 407-431.

Freudenthal, M. 1972. Deinogalerix koenigswali nov. gen., nov. spec., a giant insectivore of the Neogens of Italy. Scr. Geol. 3: 1-10.

Gadgil, M. and Bossert, W. 1970. Life history consequences of natural selection. - Am. Nat. 104: 1-24.

Givinish, T. J. 1998. Adaptive plant evolution on islands: classical patterns, molecular data, new insights. - In: Grant, P. R. (ed.), Evolution on islands. Oxford Univ. Press, pp. 281-304.

Givinish, T.J., Systma, K.J., Hahn, W.J. and Smith, J.F. 1995. Molecular evolution, adaptive radiation, and geographis speciation in Cyanea (Campanulacaea, Lobeloideae). - In: Wagner, W. L. and Funk, V. A. (eds), Hawaiian biogeography: evolution on a hot-spot archipelago. Smithsonian Inst. Press, pp. 299-377. 
Gotthard, K., Nylin, S. and Wiklund, C. 1994. Adaptive variation in growth rate: life history costs and consequences in the speckled wood butterfly, Pararge aegeria. Oecologia 99: 281-289.

Grant, P. R. 1986. Ecology and evolution of Darwin's finches. - Princeton Univ. Press.

Hasegawa, M. 1994. Insular radiation in life history of the lizard Eumeces okadae in the Izu Islands, Japan. - Copeia 3: $732-747$.

Heaney, L. R. 1978. Island area and body size of insular mammals: evidence from the tri-colored squirrel (Callosciurus prevosti ) of southeast Asia. - Evolution 32: 29-44.

Hooijer, D. A. 1951. Pygmy elephant and giant tortoise. - Sci Mon. 72: 3-8.

Kim, S.-C., Crawford, D. J., Francisco-Ortega, J. and SantosGuerra, A. 1996. A common origin for woody Sonchus and five related genera in the Macronesian Islands: molecular evidence for extensive radiation. - Proc. Natl Acad. Sci. USA 93: 7743-7748

Kozlowski, J. 1991. Optimal energy allocation models: an alternative to the concepts of reproductive effort and cost of reproduction. - Acta Oecol. 12: 11-33.

Kozlowski, J. and Wiegert, R. G. 1987. Optimal age and size at maturity in annuals and perennials with determinate growth. - Evol. Ecol. 1: 231-244.

Lawlor, T. E. 1982. The evolution of body size in mammals: evidence from insular populations in Mexico. - Am. Nat. 119: $54-72$.

Lima, S. L. 1998. Stress and decision making under the risk of predation: recent developments from behavioral, reproductive, and ecological perspectives. - Adv. Study Behav. 27 215-290.

Lima, S. L. and Dill, L. M. 1990. Behavioral decisions made under the risk of predation: a review and prospectus. Can. J. Zool. 68: 619-640.

Lister, B. C. 1976. The nature of niche expansion in West Indian Anolis lizards. I. Ecological consequences of reduced competition. - Evolution 30: 659-676.

Lomolino, M. V. 1985. Body size of mammals on islands: the island rule reexamined. - Am. Nat. 125: 310-316.

MacArthur, R. H. and Wilson, E. O. 1967. The theory of island biogeography. - Princeton Univ. Press.

Maiorana, V. C. 1990. Evolutionary strategies and body size - In: Damuth, J. and MacFadden, B. J. (eds), Body size in mammalian paleobiology estimation and biological principles. Cambridge Univ. Press, pp. 69-102.

Melton, R. H. 1982. Body size and island Peromyscus: a pattern and a hypothesis. - Evol. Theory 6: 113-126.

Mertens, R. 1934. Die Insel Reptilian. - Zoologica 84: 1-205.

Panero, J. L., Francisco-Ortega, J., Jansen, R. K. and SantosGuerra, A. 1999. Molecular evidence for multiple origins of woodiness and a New World biogeographic connection of the Macronesian Island endemic Percallis (Asteraceae: Senecioneae). - Proc. Natl Acad. Sci. USA 96: 1388613891.

Petren, K., Grant, B. R. and Grant, P. R. 1999. A phylogeny of Darwin's finches based on microsatellite DNA length variation. - Proc. R. Soc. Lond. B 266: 321-330.

Promislow, D. E. L. and Harvey, P. H. 1990. Living fast and dying young: a comparative analysis of life history variation among mammals. - J. Zool. (Lond.) 220: 417-437.

Rand, A. S., Gorman, G. C. and Rand, W. M. 1975. Natural history, behavior and ecology of Anolis agassizi. - Smithsonian Contrib. Zool. 176: 27-38.

Reznick, D. N., Butler IV, M. J., Rodd, F. H. and Ross, P. 1996. Life-history evolution in guppies (Poecilia reticulata)
6. Differential mortality as a mechanism for natural selection. - Evolution 50: 1651-1660.

Roughgarden, J. 1972. Evolution of niche width. - Am. Nat. 106: $683-718$

Sakai, A., Weller, S. G., Wagner, W. L. et al. 1997. Phylogenetic perspectives on the evolution of dioecy: adaptive radiation in the endemic Hawaiian genera Schiedea and Alsinidendron (Caryophyllaceae: Alsinoideae). - In: Givinish, T. J. and Systma, K. J. (eds), Molecular evolution and adaptive radiation. Cambridge Univ. Press, pp. 455-473.

Schoener, T. 1969. Size patterns in West Indian Anolis lizards: I. Size and species diversity. - Syst. Zool. 18: 386-402.

Shaw, C. E. 1945. The chuckwallas, genus Sauromalus. Trans. S. Diego Soc. Nat. Hist. 10: 269-306.

Shmida, A. and Werger, M. J. A. 1992. Growth form diversity on the Canary Islands. - Vegetatio 102: 183-199.

Smith, F. A. 1992. Evolution of body size among woodrats from Baja California, Mexico. - Funct. Ecol. 6: 265-273.

Sondaar, P. Y. 1977. Insularity and its effects on mammal evolution. - In: Hecht, M. K., Goody, P. C. and Hecht, B. M. (eds), Major patterns in vertebrate evolution. Plenum, pp. $671-707$

Soulé, M. 1966. Trends in the insular radiation of a lizard. Am. Midl. Nat. 100: 47-64.

Stamps, J. A. and Buechner, M. 1985. The territorial defense hypothesis and the ecology of insular vertebrates. - Q. Rev. Biol. 60: 155-181.

Stearns, S. C. 1992. The evolution of life histories. - Oxford Univ. Press.

Stearns, S. C. and Crandall, R. E. 1981. Quantitative predictions of delayed maturity. - Evolution 35: 455-463.

Stearns, S. C. and Koella, J. C. 1986. The evolution of phenotypic plasticity in life history traits: predictions of reaction norms for age and size at maturity. - Evolution 40: $893-913$

Stearns, S. C. and Crandall, R. E 1984. Plasticity for age and size at sexual maturity: a life history response to unavoidable stress. - In: Potts, G. and Wooton, R. (eds), Fish reproduction. Academic Press, pp. 13-33.

Stearns, S. C., Ackermann, M., Doebeli, M. and Kaiser, M. 2000. Experimental evolution of aging, growth, and reproduction in fruitflies. - Proc. Natl Acad. Sci. USA 97: $3309-3313$

Stock, C. 1935. Exiled elephants of the Channel Islands. - Sci. Mon. 41: 205-214.

Tamarin, R. H. 1978. Dispersal, population regulation, and K-selection in field mice. - Am. Nat. 112: 545-555.

Van Damme, R. 1999. Evolution of herbivory in Lacertid lizards: effects of insularity and body size. - J. Herpetol. 33: 663-674.

Van Valen, L. 1965. Morphological variation and width of ecological niche. - Am. Nat. 104: 589-590.

Wagner, W. L., Herbst, D. R. and Sohmer, S. H. 1990. Manual of the flowering plants of Hawaii. - Univ. of Hawaii Press.

Wallace, A. R. 1878. Tropical nature and other essays. Macmillan.

Werner, E. E. and Gilliam, J. F. 1984. The ontogenetic niche and species interactions in size-structured populations. Annu. Rev. Ecol. Syst. 15: 393-425.

Wilbur, H., Tinkle, D. W. and Collins, J. P. 1974. Environmental certainty, trophic level, and resource availability in life history evolution. - Am. Nat. 108: 805-817.

Yoccoz, N. G. and Mesnager, S. 1998. Are alpine bank voles larger and more sexually dimorphic because adults survive better? - Oikos 82: 85-98. 